\title{
Creative and Innovative Experience in Vocational Education \& Training
}

\author{
Rocío Pérez Solís, PhD. \\ Las Palmas of Gran Canary University \\ Education Department \\ Spain
}

\begin{abstract}
This paper discusses a project on the use of Theatre in Education with a group of the Superior Training Cycle Preschool Education of Vocational Education and Training, in a rural community, in the Canary Islands. Most define Theatre in Education as a general term that includes all the interactive theatre practices that help to the educational process. Some of these processes include developing original scripts, using the performance of a play as a springboard for interacting with an audience and discussing important topics or themes, or theatre activities used to support classroom curriculum. Our process helped students to build social and communicative skills, to improve students' self-esteem as well as their confidence in their academic abilities. Theatre in Education is shown to be an effective pedagogical tool.
\end{abstract}

Keywords: Theatre in education, applied theatre, creativity, innovative experience, artist-as-trainer.

\section{Introduction}

This study analyses an educational practice which provides an adequate model for both creative learning and innovative teaching. The project aims to provide a better understanding of how innovation and creativity are applied in educational practice at VET level. It analyses an educative experience on the use of Theatre in Education (TIE) and the role of creativity and innovation in Superior Training Cycle for Preschool Education. This experience is part of the Education Theatre Program (ETP) project supported by the city Town Hall of Agüimes, a rural community on the Canary Islands, which I have been leading for twelve years. The ETP promotes creativity and innovation in Education and Training through the implementation of applied theatre practices, both at primary and secondary level. All these practices need time and space out of the scheduled school to engage in more creative and innovative activities, and a major factor for success is the motivation of the teachers, tutors and other staff involved in setting up the activity, which should also translate into motivation of pupils and students. The educational actors involved in these projects see creativity as an element arising from everyday life and value its spill-over effects on learning.

Performing arts such as theatre, dance, circus arts, opera and others recently created, such as performance, define sociocultural and artistic manifestations that are distinguished by an inherent unique communicative process and for the fact that they materialise on stage through synthesis and integration of other artistic expressions which may range from literary genres to visual arts.

The sense of theatre, as a distinguishing element of the scenic fact, presents multiple forms. In this way, we can find it in a popular dance, in a cloak and sword drama and in the new proposals on stage. We must not forget other traditional expressions that currently take place in countless communities, like popular fairs, where, implicitly or explicitly, typical resources of drama are used. In that sense Harvie \& Rebellato (cited by Nicholson 2009) consider:

The theatre is everywhere, from entertainment districts to the fringes, from rituals of government to the ceremony of the courtroom, from the spectacle of the sporting arena to the theatre of war. Across these many forms stretches a theatrical continuum through which cultures both assert and question themselves. Theatre has been around for thousands of years, and the ways we study it have change decisively. It's no longer enough to limit our attention to the canon of Western dramatic literature. Theatre has taken its place within a broad spectrum of performance, connecting it with the wider forces of ritual and revolt that thread through so many spheres of human culture. 
In turn, this has helped make connections across disciplines; over the past fifty years, theatre and performances have been deployed as key metaphors and practices with which to rethink gender, economics, war language, the fine arts, culture and one's sense of self. (p. 7)

Theatrical expression, a singular and distinguishing feature in performing arts, is understood as a cultural and artistic human manifestation, a communicative act between an actor and a spectator, considering that we can apply these words to an assorted range of individuals without circumscribing them to a theatre stage. Theatrical expression has its origin and basis in the dramatic expression, which is that kind of behaviour used daily by human beings when they use the role-playing games in their communication and expression processes. Therefore, performing arts are conceived as a basic tool in a comprehensive education. It's not only responsible for studying the various forms of drama but, more importantly, by stimulating interaction it allows students to develop a wide variety of skills, whether creative ones, problem solving or those to do with personal autonomy, thus favouring communication, social interaction and self-expression.

Theatre teaching has to be a component of artistic literacy. That means watching/reading theatre, expressing themselves using theatre and talking about theatre. It implies acquiring skills which can allow people to become active and reflexive spectators by listening actively and consciously assessing and enjoying the work of art. The aim is trying to get young people to understand and appreciate the works of art as trained, critical and conscious spectators. This means, teaching to read and write in art encouraging people to understand the art in the community where they live. Using dramatic forms as teaching and learning tools allows the students to get involved kinetically and emotionally in the lessons and consequently to learn in a significant and meaningful way. In this sense, drama tools supply a comprehensive answer, a combination of verbal and non-verbal signals which provide the opportunity to have hearing, visual, motor and verbal experiences of learning at whole levels of the person, and not only merely intellectual learning, we are talking about an integral education experience.

It would seem presumptuous that, after almost three thousand years of existence, someone considers theatre as an innovation, especially when in most schools, reputable and significant drama activities are performed. School Theatre should not be only a pretty gold brooch at the end of a school year; it must be used so it is made to become a creative and cultural activity as well. We believe in a kind of theatre that is educational, playful, motivating, transversal and a multidisciplinary strategy, ideally originated in a drama project elaborated and performed by a class of students. The student, who learns this subject, learns to express, communicate and receive thoughts, emotions, feelings and internal/external ideas by using the different techniques and skills attached to performing arts. This theatrical pedagogy tries to encourage young people to participate in theatre as a learning medium and as a vehicle for social change. This new way of using theatre is known as Theatre in-Education (TIE), one of the different specific practices of Applied Theatre (AT).

\section{Theoretical Framework}

Tomás Motos (2012) claims that Applied Theatre (AT) is a rather new field of knowledge built through the study of a compendium of concrete cases, essays and theoretical reflexions published in reviews of different disciplines such as Theatre, Education, Medicine, Law, Psyquiatry or Psychology, among others. Applied Theatre (AT) has become the objective of university studies in congresses, conferences or seminars. To acquire a basic comprehension about what is Applied Theatre some works need to be mentioned such as Monica Prendergast and Juliana Saxton's book Applied Theatre (2009), and Robert Landy and David Montgomery's books Theatre for Change (2012) and Applied Theatre: Creative Transformative Encounters in the Community (Taylor, 2003). Along with them, numerous publications, like Applied Drama: the gift of Theatre (2014) and countless lectures by Helen Nicholson from Royal Holloway University of London, should also be noted. In Spain, Applied Theatre is still an unusual term, although we can find it in some university plans. In fact, even though there is no literature about (AT) in the Spanish language, it is usual to do theatrical projects using other concepts which are fit or suitable for this field of knowledge.

The Applied Theatre performances deal with matters of general interest for the community, they have to do with fears and concerns of a specific group. It is a tool for change. However, Ackroyd (2007) considers that: (...)the term 'applied theatre' is being used only for specific practices. Certain examples of practice support the discourse and construct this 'new' field in a particular mould. The discourse excludes other practices, even though they fulfil the defining features presented. 
So, rather than applied theatre being an umbrella term for a range of practices (which have specific intention, participation and operate beyond conventional theatre spaces), the term is emerging as a label for particular types of practice, (p.7). Prendergast y Saxton (2009) organise the (AT) field in nine categories: theatre in education, popular theatre, theatre of the oppressed, theatre in health education, theatre for development, prison theatre, community-based theatre, museum theatre and reminiscence theatre. Landy and Montgomery (2012) add action theatre, bibliodrama, engaged theatre, ethno drama, grassroots theatre, playback theatre, social theatre and socio drama. In many cases, the relations between these activities are unreal. Although, apparently, such different practices cannot linkage together, there is a common denominator: intentionality. All of them share the belief that theatre goes further of its aesthetical purposes and the name of (AT) works as an umbrella to find connections between all those who consider and promise with a kind of theatre which uses its power to change reality. Conrad (2004) asserts that:

The work of Bertolt Brecht in 1930s Germany was a theatrical form that influenced the development of Western Popular Theatre in the way it reclaimed theatre for political and community functions. Brecht felt that realism in the theatre encouraged passivity among bourgeois audiences, suppressing the inclination to be active participants in the theatre as in life. Brecht looked for ways to break the theatrical "fourth wall," in order to raise awareness amongst his audiences. His Epic Theatre used techniques of "alienation" within the dramatic action, including episodic scenes interrupted by narration, songs, parables, the projection of texts and images, to break the illusion of the performance, to make audiences active interpreters of the multi-layered text rather than playing on their emotions, (p. 13).

While many educators find that this critical pedagogy appeals ideologically, some have found the transition from ideology to praxis difficult. One route for making the transition from theory to practice combines critical pedagogy with interactive performance practice. This combination creates a learning community that empowers participants, which generates critical understanding, and which promotes transformation-all goals of critical pedagogy and the interactive performance techniques of Augusto Boal. In one enactment of Boal's Theatre of the Oppressed (TO), student performers created an interactive drama that explored issues of body image and related social pressures. As a result of their participation in the process, they learned about personal behaviors related to eating and body image, initiated critiques of cultural norms and expectations, and developed a richer understanding of the performance process. Historically, the works of Paulo Freire (1970) and Augusto Boal (1979) have provided a strong link between applied drama, social justice and education. Freire is seen by many educational philosophers and practitioners as "the inaugural philosopher of critical pedagogy" (cited by Freebody \& Finneran, 201, p. 49). Central to Freire's work was the notion of conscientizacao, a term referring to the need to learn to perceive social, political, economic contradictions and fight against oppressive elements of society (Freire 1970) ${ }^{1}$. Freire criticized pedagogy in which the teacher discusses reality as if it were static and unconnected to the world of the student. The proposal of Augusto Boal - Brazilian playwright and social educator-, inspired by the thought and praxis of Paulo Freire, is one of the most iconic traditions of social, critic and committed theatre, with its proven experimentation in communities and schools. In the Theatre of the Oppressed (TO) participants denounce social situations or express their experiences of fear, oppression or exclusion. Through participation and dialogue, ways to resolve conflicts or to find more justice and solidarity, transformative alternatives through roleplaying games, exchange of papers and other various dramatic techniques are always looking. Body language, conflict management, communication experience, affective-relational dimension and the role of the collective subject are some of its identity.

Helen Nicholson (2005) asserts that the intentionality of the workers in AT's field "develop new possibilities for the daily life more than separate the fact of going to the theatre from other aspects of life" (p. 4). On the other hand, for Ackroyd (2007) applied theatrical projects have made positive contributions to the daily life of individuals and communities in a variety of contexts.

Prendergsat and Saxton's (2009) suggest that, when we make (AT), there's a series of common functions and features inside the process:

- Facilitation function used in AT is essentially based on strategies and theatrical and education techniques closely linked with the good pedagogical practices. That means "the facilitator must be able to sense and

${ }^{1}$ I am using $49^{\mathrm{a}}$ edition (12a , Spain), May 1992

30 
serve the needs of the audience and create a safe container for individual self-expression as well as manage the segues among performance of scenes, spectator interventions, processing the results of dramatic ideas from the audience, and direct communication with the audience" (p.18).

- The scripting of an Applied Theatre performance is a collaborative and negotiated process between the target group, for whom the content is significant, facilitators, and/or playwrights who should be qualified and experienced enough.

- Play building is the root theatre activity of applied theatre practice and is a constant process of negotiated meaning-making. Play building is also called "collective creation" or "devising". It is the form used in which the dramaturge is not an external writer, but the storyline is being built during the rehearsals in a collaborative process where all the members in the group participate. That changes radically the work relationships and the way the process is faced. Occasionally, these shows are not "theatrical production" in a traditional way but rather a serial of monologues or plots built about a specific matter. The storyline created like this can take just one direction, a story with a linear plot or, on the contrary, incorporate multiple intertwined stories -that is, nonlinear narrative.

Theatre in-Education (TIE) field allows teachers to work with a new methodology open to creativity. Innovative means involve research as part of the educational process, stimulating an independent search of new ways; leading to a change of mentality, symbols or stereotypes; making possible the development of a critical capacity, self-reflection and interpretation of practices, aiming at the achievement of a comprehension of the world as a form of new conscience. Freire (2006) says: "teaching without learning does not exist" (p. 24) in the sense that teaching is not transferring just knowledge if not to create the possibilities of its production or its construction.

We know students participating on drama usually improve in comprehension, assistance record and compromise with school, besides the fact that their marks are higher than their classmates. Schools with integrated arts programmes, even in depressed areas, get a high academic performance. Last approaches on education theatre focus on studying the impact of theatre on moral and social learning. In this sense, Needlands (2008a) states that the real significance of theatre with teenagers lies in social and artist implication (participation) process and in experimental situations and experiences more than in the results or in the artist's product which can be obtained. The contribution of this model of theatre based on the group is learning to act as a whole, as an artist and as a social group. The main feature of theatre made by young people is the commitment of making theatre from a collective point of view (Nederlands, 2008b).

Theatre and theatrical techniques insist on participation and collaboration, they favour the harmonic relationship between the members of the group as it allows participants to become aware of collective work and intends to make it with the support of everybody, since it creates a need of precise and clear communication.

The effects of theatre go further than the narrow walls of a classroom and make an impact on the young people's quality of life. A pro-social way of understanding education theatre contrasts with a pro-technical model limited at learning theatre as a curricular subject. In this way, preferences are given to technical knowledge about periods, playwrights, styles and theatrical genres. For social theatre, the important thing is to build a common culture guiding children to find out new ways of living together instead of one against the others, searching solidarity and creating new models of plural communities.

To develop dramatic action, we should use the same resources as we do in real life: linguistic expression, corporal expression, plastic expression and rhythmical-musical expression in a coordinated and simultaneous way. The problem, is that these types of expression are studied in Spanish schools in a separate way. Moreover, only theatre is capable of linking them. A theatrical script can be read and represented in some different ways, maybe contradictory, but always fun, which is the main incentive.

\section{The Project}

Our project takes place in a VET center in the rural community of Agüimes. It is placed in the southeast of Gran Canary Island, where 25,000 people live in three differentneighborhoods. I have run the Education Theatre Program (ETP) supported by the city hall of Agüimes from twelve years ago, in which an average of 2.000 students participate every year, all of them coming from different schools on the Gran Canary Island. During one week in May, students from pre-school, primary and high school watch and play theatre and make different pedagogical activities in relation with the theatrical field. The project of educational theatre with Superior Training Cycle Preschool Education students in VET is designed to participate in ETP. 
At the beginning, we thought of a course with a length of 2 weeks. For this purpose, we invited an artist to give a two-day's workshop. However, the students were so motivated that the project lasted for three weeks and the artist joined in the process along with the pedagogical staff.

The project became a cross-curricular plan between these subjects: Personal Autonomy, Children's Health, Motor Skills and Cognitive Development, Infant Education Didactics, and Expression and Communication Skills. Teachers took the decision to work with an artist considering their lack of theatrical education and, as mentioned before, because theatrical education should have a component of artistic literacy. The model ${ }^{2}$ of the pedagogical artist (Laferriere, 1997) allows the linkage between the teacher with no artistic training and the artist with no pedagogical training. We need both types of education to teach theatre in an educational context. The culmination of the project was a collective stage creation called Cinderella's Birthdayy which consisted of two performances especially aimed for a preschool audience. This took place in the main Theatre inside Education Theatre Program (ETP). They worked on children's self-esteem and sex roles through specific elements as fantasy and humour. During the work in progress, the teachers Andrés Díaz and Plácida Vega (2012) as artistic directors had a main objective: students should learn through experience. The performance had a clear relationship between the perception of "me" and "others" and at preschool stage, drama takes the child to know himself and to recognize his own value, producing positive effects on his self-esteem, his capacity to evaluate his achievements and his mistakes. It will give him the opportunity to improve life.

\section{Methods}

The project was designed to explore a participative methodology with Theatre in Education (TIE) as a pedagogical tool, that enable the process of teaching that makes students easy to express their feelings and emotions not only with words but also with their bodies. Encouraging learning skills, creative thought, conflict resolution, self-esteem, tolerance with other students, and comprehension of different points of view and search of solutions that benefit the group, guided by the following investigation questions:

- Does Theatre in Education (TIE) facilitate the student's didactic tools that the teachers could apply in their professional life in their work with children?

- Is TIE effective as a pedagogical tool? What are its effects?

- In what way does teamwork favour the development of habits of responsibility?

This is an exploratory study of qualitative approach by means of the ethnography participant as a primary form to get information followed by interviews with the participants. Based on the audio and videotapes we made throughout the process, my journal and field notes, and students journals, the scripts depict instances of per formative interaction, discussion, the devising process, the scenes that students created, the animation of these scenes, responses to our performances and the interview I conducted with teachers and students. This structure generates studies of rich cases in information in a social constructivist framework, with the aim of "specific cases that generate a deep comprehension inside a particular context" (Patton, 2002, p. 546). Although the two-day theatre workshop was initially conceived as an independent experience from the performance, it naturally ended up becoming an important part of the work. It provided an opportunity to analyze intensively the dynamic of the group through discussions, filming and making a critical view over the live work.

${ }^{2}$ Laférriere has conceptualized the profile of a pedagogue-artist with this feature:

-Dosing knowledge, know to do and know to be

-Situate the pleasure in the work and in the game: build the passion and pleasure in learning

-Having self-confidence in itself and in the others

-Knowing to use flexibility a rigor

-Integrating the person and events

-Knowing how to listen the environment, people and events

-Using mixed techniques

-Having surprising elements in reserve to create certain effectsas well as the necessary competency of production to challenge the problems associated with the teaching staff of the performing arts. He picks up basic skills and abilities which should be acquired by the professionals in education theatre. They should be able to transfer the theory to practice. 
Finally, the participants in the project were 24 students, 4 teachers and one ethnographer. The process began with a series of games and activities for group building, trust building and skill development, moved on to the exploration of themes through brainstorming, image work and discussion, then into devising, storytelling of incidents from their lives and finally the creation of scenes based on these stories. As we created the scenes, we animated them to explore the issues raised, using techniques adapted from Boal's Theatre of the Oppressed.

Through one training seminar and coaching celebrated during January, -one of the goals of ETP is providing techniques and tools to teachers- so as to use them as methodology to make students have fun while learning, showing work with some artistic quality, educating their attention and achieving the cultural competence required. The ETP has generated a social fabric among the younger population sector, their families, school and institutions around the Performing Arts in the community. The group was presented as a pedagogical laboratory and the number of viewers amounted to 300 students, aged 3 to 5 years, and 200 adults among relatives, teachers from other centres and companions, a total of 500 spectators in all. With this experience, they could make the evaluation of the play and the process. After that, I interviewed the teaching staff and subsequently some days later assessed the students on the experience collected.

\section{Results}

The results of this study confirm that the students learned applied techniques for their professional life working with children. The use of structures of dramatic play facilitated the formation of identity of the students as change agents in the field of teaching, helping to strengthen learning, cooperation, trust and empathy, which demonstrated in both the learning experience and in the building of the drama and definitely contributed to positive academic achievements and a significant development of expressive skills. The group of students seemed to generate a sense of power as a result of their experiencing this theatrical success with the children and I dare say there was a positive reinforcement among the professional teachers from other schools who were watching the work, which had an obvious positive impact, as it raised the self-esteem of the students and generated a feeling of identity and belonging to the professional group they were aspiring to become part of. It increased notably the commitment to the classroom and to the academic project. In this sense, Theatre in Education (TIE) is undoubtedly shown to be an effective pedagogical tool.

\section{Conclusions}

This good practice of creative learning and innovative teaching provides a way to reduce the gap between the current emphasis on summative evaluation and the lack of means to incorporate creativity into it, while at the same time allowing teachers to evaluate both the process and the result. It is noted that education and culture form a substantial part of community development and personal growth of the people living in it, thus training in TIE and 'making' culture at the same time is of immeasurable value. The experience offers a paradigm to engage students and develop habits of responsibility. More research is needed to explore the potential of these dynamics and their effects on different environments, this study being only one approach to these teaching experiences that generate changes in students. Theatre in this environment facilitates understanding of the cultural and academic obstacles faced by young students, and becomes a concrete powerful means to achieve what Freire (1992) calls "the vital knowledge".

PhD. Rocío Pérez Solísis associate professor at the Department of Education at the University of Las Palmas of Gran Canary, Spain. Her research interests focus on education and theatre, communicative skills, creativity in the teaching-learning process and also gender studies. Belongs to the group of research and educational innovation of evaluation and learning of the ULPGC

\section{References}

Ackroyd, J. (2007). Applied theatre: An exclusionary discourse. Applied Theatre Researcher, 8(1).

Banaji, S., Perrota, C. \&Cranmer, S. (2010). Creative and Innovative Good Practices in Compulsory Education in Europe. Luxembourg: Publications Office of the European Union.

Boal, A. (2009). Teatro del oprimido. Barcelona: Alba Editorial.

Boal, A. (2011). Teatro oprimido. Cuadernos de Pedagogía, (411), 46-51.

Conrad, D. (2004). Exploring risky youth experiences: Popular theatre as a participatory, performative research method. International Journal of Qualitative Methods, 3(1), 12-25. 
Freebody, K. \&Finneran, M. (2013). Drama and Social Justice: Power, Participation and Possibility. In Anderson, M. \& Dunn, J. (Ed.). (2013). How Drama Activates Learning. (47-64). New York: BloomsburyAcademic. Freire, P. (1992). Pedagogía del oprimido. Madrid: Siglo XXI.

Freire, P. (2006). Pedagogía de la autonomía: saberes necesarios para la práctica educativa. Madrid: Siglo XXI. Laferrière, G. (1997). La Pedagogía puesta en escena. Ciudad Real: Ñaque.

Motos, T. (2009). El Teatro en la Educación secundaria. Revista virtual: Creatividad y Sociedad, 14.

Motos, T. (2012). Otros escenarios para el teatro: el teatro aplicado. Ñaque. Teatro Expresión Comunicación. Núm. 73 diciembre 2012-febrero 2013, p. 6-159

Needlands, J. (2008a). Acting together: ensemble as a democratic process in art and life. Próximapublicaciónen Research in Drama Education.

Needlands, J. (2008b). Essentially Youth Theatre. NAYAD Starting the Debate Seminar, May 10th 2008. Retrieved from http://nayad.ie./files/jNeedlandsadress.pdf

Nicholson, H. (2009). Theatre \& Education. New York: Palgrave Macmillan.

Nicholson, H. (2014). Applied drama: The gift of theatre. New York: Palgrave Macmillan.

Patton, M.Q. (2002). Qualitative Research and Evaluation Methods, 3rd edn. London: Sage Publications.

Prendergast, M., \& Saxton, J. (2009). Applied theatre: International case studies and challenges for practice. Intellect Books.

Landy, R., \& Montgomery, D. T. (2012). Theatre for change: Education, social action and therapy. Palgrave Macmillan.

Taylor, P. (2003). Applied theatre: Creating transformative encounters in the community. Heinemann Drama. 